meeting of the Division, if any question of urgent importance should arise as a result of this interview.

Dr. Moras then submitted his tabled motion dealing with the conditions of entry into the Nursing Service of the District Mental Hospitals. He stressed the importance of an adequate primary education, which, he stated, was essential if the nurse was to take advantage of subsequent training. The motion was fully discussed and, in a slightly amended form, was unanimously agreed to. The amended motion reads: "That conditions in the nursing service in the district mental hospitals should, as far as possible, be standardized; that probationers should enter the service on the report of the Resident Medical Superintendent and as a result of a qualifying examination, and that appointments should only be made to permanent staffs when probationers have passed the Final Nursing Examination". The Secretary was directed to forward a copy of this motion to the medical superintendents of the district mental hospitals and to the inspectors of mental hospitals.

The meeting accepted with pleasure Dr. Donelan's invitation to hold the Spring Meeting at Portrane Mental Hospital on Thurdsay, April 5, 1934.

Dr. Kelly, Inspector of Mental Hospitals in the Irish Free State, as a representative of the Irish Division on the Irish General Nursing Council, reported that, although the Irish General Nursing Council had recognized the Association's certificate for registration, a nurse so registered was not recognized as such by the English General Nursing Council.

Dr. LFEPER pointed out that this condition of affairs was only to be expected until agreement was reached between the Association and the General Nursing Councils of England and Scotland as had been done in the Irish Free State.

Dr. Mills opened a discussion on "Occupational Therapy". He stressed the importance of providing occupations which would appeal to the natural interests of the patients, such as all forms of farm work and gardening, etc., in an agricultural community. He showed an example of handicraft on which his patients were working, but stated that, in his opinion, the pure handicrafts had a limited scope and usefulness.

Dr. Mills's paper gave rise to an interesting discussion, which was contributed to by Dr. Nolax, Dr. Greexe, Dr. Donelan, Dr. Kelly and Dr. Keene. Dr. Nolas gave a description of the high state of efficiency to which this form of treatment had been brought in Holland.

The Chairmax thanked Dr. Mills for his interesting and helpful paper.

\title{
CITY AND UNIVERSITY OF BIRMINGHAM JOINT BOARD OF RESEARCH FOR
} MENTAL DISEASE.

An Exhibition and Demonstration of the Research Work of the Joint Board and of other Midland Mental Hospitals was held on November 27, 1933, at Hollymoor Mental Hospital.

Dr. F. A. Pickworth, the Director, gave the following address:

About 140,000 people receive treatment for mental disorder in England and Wales at a cost of ten million pounds annually. Of this cost only 35 . out of every hundred pounds is spent upon fundamental research into the primary causes of mental disease, whereas similar research on cancer is supported by an annual expenditure of hundreds of thousands of pounds. The suffering of the patients, and especially the distress of the relatives, may even surpass that caused by cancer, and the reasons for the meagre financial support for mental research must be sought elsewhere. The undue exaggeration of the importance of hereditary factors, which has branded mental research with such hopelessness, is chiefly responsible for the lay attitude, whilst the research worker himself finds the lack of correlation with general medicine a serious difficulty.

For the purposes of attracting funds for research one must be in a position to demonstrate the economic value of any particular line of work proposed; this is only possible by a study of the basic principles of mental research and a survey of the materials and opportunities available. In the short time which the introduction to my exposition of our work permits, I will briefly refer to some of these principles and associated difficulties.

Research may be followed along many lines of a different category. It is hardly necessary to point out that the most essential and urgent of these is the searching out of the predisposing factors and exciting causes; since all other research is necessarily hampered by lack of knowledge in this field. A complete knowledge of the causes, however, is not in itself the whole problem; hence the team-work of hospitals where many different lines are being investigated at the same time. There is a colossal and increasing literature on the subject, mostly descriptions of behaviour with superficial associations and classifications not easily correlated with general medicine.

There is a disappointing diversity of opinion as to the fundamental causes of insanity, which learned and experienced observers deduce from clinical observations, the effect of which is to 
minimize this most valuable of all methods of medical research. One cannot but admire the mass of evidence which bio-chemists have obtained by patient skilled research into the variations of physiological constituents of the body-fluids, but it is noteworthy that many of these are apparently contradictory, thus necessitating further evidence for their satisfactory correlation. The course of mental disease does not fit in exactly with an infection as understood by the presentday conceptions of pathology and bacteriology. The most valuable source of material for study is undoubtedly the cadaver, but even here the length of time between the activity of the causa agents and death may be sufficient for complete resolution of all demonstrable pathological lesions, whilst the processes leading up to and culminating in the death of the patient may hopelessly mask the clinical picture.

The research worker is yet further harassed by the knowledge that mental disorder (as distinct from memory and intellectual defect) is of the nature of a functional disturbance of physiologically intact mechanisms within the brain, since remissions may occur during which the individual is sane. Even mute apathetic cases of dementia præcox may show a short temporary resuscitation of their powers of rational conversation by means of suitable cerebral stimulation. We thus encounter some well-defined limitations to the field of mental research. If the anatomical integrity of the nervous structures, which subserve the processes of mind, can be established in cases of mental disorder, then it is useless to search for gross pathological changes in those nervous structures as evidence either of ætiological cause of the mental disorder or of regional localization of the disturbance of the mind within the brain. We can, however, in this connection clearly demonstrate pathological changes in other parts of the brain, presumably concerned with memory and intellect, and by inference deduce that neighbouring nerve structures have their function seriously interfered with. Such limitations are of inestimable value in saving waste of time, energy and material in useless directions. A further narrowing of the field of research occurs in that much necessary work has already been done by experienced investigators. On the other hand, medical research is constantly opening up new special lines, and of great use to us are the recent increases in our knowledge of pituitary gland hormones, and the determination of the metabolic functions of cell groups of the hypothalamus. Such work helps us to explain some hitherto puzzling results, since we now know that a difference of $\mathrm{I} \mathrm{mm}$. or so in the regional localization of irritation within the brain-stem may cause different effects upon the body chemistry.

In view of the narrow field of research open to us we must attach supreme importance to any discovered facts which are independent of the observer's opinion; and thus the late residua of infections, for example, antibodies in the blood, fibrosis of viscera and blood-vessels, and hyperplastic membrane of the nasal sinuses, fossil-like, offer far-reaching evidence from their characteristics.

With this introduction I now proceed to tell you of the work of the Joint Board during the years $1923-1933$.

Sir Frederick Mott, the Board's first Director, had exceptionally wide experience and achieved world fame in neurology; his untimely death in 1926 was a sad loss to the Board. His lifelong research in mental disorder led him to believe that the primary causes were to be found in the study of the endocrine glands : hence all the work at Birmingham was directed ultimately towards the one object. Personally, I had the honour of knowing Sir Frederick before coming to Birmingham, and I derived great pleasure from discussing these problems with him. Shortly before his death he re-affirmed his belief in the disturbed endocrine origin of insanity. The oral sepsis theory of Dr. William Hunter, also of Charing Cross Hospital, was fully discussed with a view of applying the knowledge to research in mental disorder, but only the enthusiasm and encouragement of Dr. Graves enabled me to persuade Sir Frederick to permit much research into the bac teriology and pathology of chronic sepsis. Had Sir Frederick lived to see the present results I am sure he would have been completely convinced of their value.

With the endocrine theory in view Sir Frederick consulted Prof. J. S. Haldane on the determination of basal metabolism and its application to mental patients, and the Medical Research Council provided us with the funds for the building of a respiration chamber to be fitted up as a bedroom. The difficulty at first experienced with accurate determination of the very minute variations of the composition of the air in so large a chamber required special research, lasting about two years.

Although the chamber method obviated much of the apprehension of the patient, such as would have occurred with a face mask, yet occasional irregular movements of patients prevented accurate determination of the basal figure. Later, we decided to do the experiments during the early hours of the morning whilst the patient was asleep in the chamber, and many were the sleepless nights my assistant and I had in order to make observations and collect specimens for analysis.

What appeared to be a simple problem in mental disorder was the investigation of the part played by the thyroid gland. Insufficiency of thyroid secretion in children was the recognized cause of cretinism, and the associated mental hebetude could be readily cured by the simple 
administration of thyroid substance. We removed thyroid glands from cases of mental disorder post-mortem and determined by chemical methods the iodine content of the gland. This was correlated with the clinical condition and a complete histological investigation. In a few cases the biological effect upon the growth of tadpoles was also studied. We found that some cases had very little active secretion, but others showed quite a large amount. Variation from the normal appeared to be the important finding. This variation was greatest in septic conditions, and naturally suggested damage of the thyroid by naso-oral sepsis.

In the course of the examination of the central nervous system of a case of myxœdema we found, near the brain vessels, irregular masses of colloidal substance, probably similar to the mucin infiltration occurring in other parts of the body in myxœdema. The mental symptoms, therefore, could be explained as being due to disturbed function of nervous tissue consequent upon the mechanical obstruction to the blood or fluid supply of the neurons.

We next tried to discover anatomical changes in the brains of animals following treatment with hypnotic drugs, and found accumulations of mucinoid substance similar in appearance to that seen in the myxœdema case.

The search for toxins in the blood as a possible cause of disturbed neuron function naturally led us to study intestinal infections. In I9I7 no fewer than I, I43 deaths from dysentery had occurred amongst roo, 000 asylum inmates. Application of the Widal reaction showed that about one-quarter of the patients in the Birmingham Mental Hospitals had been infected with organisms of the typhoid-dysentery groups. As new admissions showed approximately the sarne figure, such infection occurred in most cases prior to the onset of mental disorder.

A very interesting outcome of this research was the finding of abnormal response in the formation of agglutinins to typhoid vaccination. We found that, whereas under normal conditions vaccination and infection agglutinins persisted in the blood for several years, in our patients they sometimes disappeared in a few weeks. We also encountered the phenomena of no response to a particular antigen and the appearance of heterologous antibodies upon injection of T.A.B. antigen. Evidence was thus obtained that many patients had had previous infection with organisms of the food-poisoning groups. The Oxford Standard cultures were used from I925 onwards. In 1926, I4 typhoid carriers were detected and isolated, and in the same year one fatal case of dysentery occurred.

We carried on simultaneously several research schemes which have proved unfruitful, e.g., our bacteriological examination of infected teeth was surpassed by the publication of a more comprehensive research elsewhere, and the biopathological tests which we made for viruses in the brains obtained post-mortem from patients were all without positive result.

After the publication of our work on the thyroid gland in 1925, Sir Frederick decided to investigate the pituitary gland, and we removed the gland in siti for histological study. Almost by accident it was noted that the adjacent sphenoidal sinus sometimes contained pus. This necessitated a side-tracking of the research upon the pituitary to the special examination of the adjacent sphenoidal sinus. The results of this side line have amply justified the investigation, for we were soon able to show that sepsis adjacent to the pituitary was a factor in causing abnormal masses of colloid in the gland. Such colloid separated the anterior from the posterior lobe, and doubtless was associated with disturbed physiological activity. Similar separation occurs in Simmonds's disease, where extreme wasting and other systemic disorders occur, referable to a disordered function of the adjacent brain-stem to which the pituitary supplies hormone. The work of the sphenoidal sinus has since been extended to include the other nasal sinuses, and still occupies an important proportion of our work.

The finding of sepsis so near the brain suggested that chronic symptomless infection of a microscopical character occurred oftener than was generally supposed. Accordingly a large number of sphenoidal sinuses were sectioned to find out whether organisms could be traced through the thin bone separating the sinus from the pituitary fossa. Many gave negative results; then a case came along which typified our expectations. Masses of organisms were seen invading the sphenoidal sinus mucosa, submucosa, bone, pituitary capsule and the gland itself. Infection of post-mortem origin could be definitely ruled out by the finding of myriads of organisms embedded in large masses of pituitary colloid, which could not possibly have produced such a reaction within the nineteen hours which elapsed between death and formalin fixation of the tissue. In I928 nearly half of the sphenoidal sinuses examined showed some or other evidence of past infection. Parallel with this work Dr. Graves investigated the clinical aspect of sinusitis, and obtained evidence of sphenoidal infection in $37 \%$ of the cases examined by the Watson-Williams technique. Also by the co-operation of Mr. Stirk Adams I was able to examine bacteriologically the saline wash-outs of the cases investigated.

Our chemical investigations, at that time ably carried out by Dr. Woodhouse, were directed to the solution of some problems concerning lecithin and cholesterol. We attempted to find out whether there was an association between the constituents of the adrenal glands, the gonads and the brain in cases of mental disorder. Amongst our findings the low values of phosphatids 
in cases of confusional insanity and the high value in epileptics were of considerable importance.

The relation of anoxæmia of the brain was studied with reference to the literature, and the accumulated information made the subject of an article in the Mott Memorial Volume. As an outcome of this we examined the blood-pigments to ascertain whether there existed forms of hæmoglobin which were useless for respiration. The results proved the value of a carefully planned research, for not only did we find a large number of cases with $2-12 \%$ of useless pigment in the blood, but also the expected correlation of such cases with a positive Widal reaction characteristic of previous intestinal infection could be definitely asserted. The oxygen capacity of the blood was determined and compared with the estimation of hamoglobin by the Stadie-cyanohæmoglobin method, the Fleischl-Meischel hæmoglobinometer and by actual titration of the iron content. Abnormal pigment was demonstrated in 28 of roo cases. Animals injected with T.A.B. or streptococci showed no increase of abnormal pigment, but when $B$. nitrosobacter or enteritidis Gaertner was injected, 7-15\% of inactive pigment could be detected.

Permeability tests of the red blood-corpuscle to various substances were carried out also in conjunction with Dr. Woodhouse. After showing the ready permeability to bromides and the impermeability to sulphates, we employed these substances as test mixtures for quantitative determination of the ease with which other added substances could penetrate the corpuscular envelope. We also determined that some salts penetrated into masses of raw egg-white at a greater rate than others, so that not only the red corpuscle envelope but also its contained protein is concerned in selective permeability.

The permeability of the choroid plexus and brain membranes was investigated in our laboratory by Dr. Strecker. The increase of permeability in general paralysis and the decrease in dementia pracox were generally confirmed, and useful additions to our knowledge of permeability obtained by animal experiments under different physiological conditions.

In 1925 I collected the carotid arteries from 50 consecutive post-mortems on mental patients. Without exception all showed slight but definite atho-sclerotic changes at the junction of internal and external arteries. Gross calcification of brain arteries occurred in a large proportion of cases. The necessity for a study of the brain capillaries became obvious, but the insuperable difficulties of all injection methods precluded their use. After two years' experimenting we developed a method of staining the contents of the blood-vessels, which enabled us to see exactly what was required, namely, states of anæmia or congestion in various regions of the brain and abnormalities of the blood-supply, such as capillary leakages and microscopic hæmorrhage. The field opened by this method is a large one, not only in mental research, but there are applications in physiology, anatomy, and especially pharmacology. Its probable value in the localization of the mind within the brain is unsurpassed, but with my present staff (entirely of unqualified assistants) results of value can hardly be expected before several years.

A glance at our annual reports will show the enormous mass of routine work necessary in order to discover results of value by the indirect method. Such work is, however, a very necessary field of research, and is invaluable to the clinical investigations of the hospitals sending specimens. On this basis the Joint Board has so far justified the expenses incurred, and it is hoped that the importance of the work will in future attract more practical interest and co-operation.

Five groups of slides were then shown. Each slide was briefly explained, and correlations made with mechanisms by which dysfunction of the brain might occur:

(I) 8 slides: Agglutination results.

(2) I I slides: Pituitary affections due to sphenoidal sinusitis.

(3) 28 slides: Nasal sinus sepsis.

(4) 3o slides: Capillary changes in brain-tissue.

(5) 18 slides: Subjects of diverse general interest.

List of Exhibits.

Barnsley Hall (Worcester County): Agenesis of cerebellum. Enucleated eye and avulsed testis.

Burghill (Hereford County):

Pick's atrophy of the brain.

Brain showing webbing of cingulate gyri.

Brain of newly-born child.

Blood films-immature leucocytes.

Media for isolation of typhoid from sewage.

Stereo-photo spirochætes in G.P.I. 
Burntwood (Stafford County):

Brain of microcephalic idiot.

Cheddeton (Stafford County) :

Method of mounting museum specimens to preserve colour.

Coleshill Hall (Colony for Mental Defectives):

Albums showing photographs of types of mental defectives.

Hatton (Warwick County) :

Publications.

Hollymoor (Birmingham City):

Photo of Hodgkin's disease.

$\mathrm{X}$-ray photographs of case of osteitis fibrosa with tibia.

$\mathrm{X}$-ray photographs of Paget's disease.

Publications.

Humberstone (Leicester City):

Museum specimens showing causes of sudden death.

Vernes syphilometer.

Monyhull (Colony for Mental Defectives) : Publications.

Narborough (Leicester and Rutland):

Pial tumour simulating pituitary tumour.

Publications.

Powick (Worcester County and City): Waterproof sheeting, etc., swallowed by patient.

Rubery Hill (BIrmingham City) : Case photographs illustrating recovery. Photographs showing cranial nerve paresis. Tabulated findings-clinical nasal sinusitis. Publications.

Stafford (Stafford) County) :

Brain with tuberose sclerosis

Cerebellum gliosis.

Apparatus for detection of acetylcholine in blood.

Winson Green (BIRMingham City):

Sarcoma of brain.

Joint BoARd of Research fOR Mental Disease :

Cerebral hæmorrhage, 33 specimens.

Meningitis, 6 specimens.

Residua of subdural hæmorrhages, 8 specimens.

Thickening of brain membrane, 6 specimens.

Subdural hæmorrhages, 12 specimens.

Nasal sinuses in association with cerebral vascular defect, I 3 specimens.

Atheroma of cerebral vessels, 6 specimens.

Cerebral softening, 9 specimens.

Tumours of central nervous system, I4 specimens.

General paralysis: Atrophy of cortex, frosting of ventricles, 4 specimens.

Pituitary gland abnormalities due to nasal sinusitis, I 5 specimens.

Nasal sinuses, frontal and ethmoid, i i specimens.

,, sphenoidal, 6r specimens.

antra, 99 specimens.

Miscellaneous specimens of pathological interest.

Cardiac lesions, 9 specimens.

Gall-bladder, I6 specimens.

Intestine and mesentery, I 5 specimens.

Stomach mucosa: Atrophy and vascular affections, i I specimens.

Injected specimens illustrating passage from naso-pharyngeal to intra-cranial infection.

Experimental sinusitis in animals.

Dry bone specimens.

Photographs of capillary blood-supply of the brain.

Chemical, bacteriological and histological apparatus and methods (in the laboratory).

LXXX. 